\title{
The SCRAP rule: The Derivation and Internal Validation of a Clinical Decision Rule for Computed Tomography of the Chest in Blunt Thoracic Trauma
}

\author{
Julien Payrastre, MD*; Suneel Upadhye, MD*; Andrew Worster, MD, CCFP(EM)*; Daren Lin, MD*; \\ Kamyar Kahnamoui, $\mathrm{MD}^{\dagger}$; Heather Patterson, $\mathrm{BScN}^{\ddagger}$; Layli Sanaee, $\mathrm{BSc}^{\S}$; Rob Clayden, $\mathrm{BSc}^{\S}$
}

\section{ABSTRACT}

Objective: To derive and internally validate a clinical decision rule that will rule out major thoracic injury in adult blunt trauma patients, reducing the unnecessary use of chest computed tomographic (CT) scans.

Methods: Data were retrospectively obtained from a chart review of all trauma patients presenting to a Canadian tertiary trauma care centre from 2005 to 2008, with those from April 2006 to March 2007 being used for the validation phase. Patients were included if they had an Injury Severity Score $>12$ and chest CT at admission or a documented major thoracic injury noted in the trauma database. Patients with penetrating injury, a Glasgow Coma Scale (GCS) score $\leq 8$, paralysis, or age $<16$ years were excluded.

Results: There were 434 patients in the derivation group and 180 in the validation group who met the inclusion criteria. Using recursive partitioning, five clinical variables were found to be particularly predictive of injury. When these variables were normal, no patients had a major thoracic injury (sensitivity $100 \%$ [95\% Cl 98.4-100], specificity $46.9 \%$ [95\% $\mathrm{Cl} 44.2-46.9$ ], and negative likelihood ratio 0.00 [95\% Cl $0.00-0.04]$ ). The five variables were oxygen saturation $(<95 \%$ on room air or $<98 \%$ on any supplemental oxygen), chest radiograph, respiratory rate $\geq 25$, chest auscultation, and thoracic palpation (SCRÄP). In the validation group, the same five variables had a sensitivity of $100 \%(95 \% \mathrm{Cl} 96.2-100 \%)$, a specificity of $44.7 \%(95 \% \mathrm{Cl}$ $39.5-44.7 \%)$, and negative likelihood ratio of $0.00(95 \% \mathrm{Cl}$ $0.00-0.10)$.

Conclusions: In major blunt trauma with a GCS score $>8$, the SCRAP variables have a $100 \%$ sensitivity for major thoracic injury in this retrospective study. These findings need to be prospectively validated prior to use in a clinical setting.

\section{RÉSUMÉ}

Objectif: L'étude visait à obtenir par dérivation et à valider par voie interne une règle de décision clinique permettant d'écarter la présence de blessures thoraciques graves chez des adultes ayant subi un traumatisme contondant, ce qui diminuerait la nécessité de recourir inutilement à la tomodensitométrie (TDM) du thorax.

Méthodes: II y a eu une collecte rétrospective de données à partir d'un examen de dossiers de tous les traumatisés traités dans un centre de soins tertiaires au Canada, de 2005 à 2008; ceux traités d'avril 2006 à mars 2007 ont servi à la phase de validation. Les patients étaient sélectionnés s'ils avaient obtenu un résultat $>12$ à I'Indice de gravité de la blessure et qu'une TDM avait été effectuée à l'arrivée ou encore s'ils présentaient une blessure thoracique grave avérée d'après la base de données sur les traumatismes. Par contre, les patients étaient écartés s'ils avaient subi une blessure par pénétration, avaient obtenu un résultat $\leq 8$ sur l'échelle de Glasgow (EG), étaient atteints de paralysie ou étaient âgés de $<16$ ans.

Résultats: Quatre cent trente-quatre patients dans le groupe de dérivation et 180 patients dans le groupe de validation répondaient aux critères de sélection. Cinq variables cliniques particulièrement justes quant au caractère prévisionnel des blessures se sont dégagées du partitionnement récursif. Lorsque ces variables étaient normales, aucun patient ne présentait de blessure thoracique grave (sensibilité, 100\% [IC à 95\% 98.4-100], spécificité, 46.9\% [IC à 95\% 44.2-46.9], rapport de vraisemblance négatif, 0.00 [IC à 95\% 0.00-0.04]). Les cinq variables en question étaient la saturation en oxygène $(<95 \%$ à l'air ambiant ou $<98 \%$ en cas d'oxygène d'appoint), la radiographie pulmonaire (chest), une fréquence respiratoire $\geq 25$, I'auscultation thoracique, et la

From the *Division of Emergency Medicine, †Department of Surgery, $¥$ McMaster Hospital, and §McMaster University Medical School, McMaster University, Hamilton, ON.

The abstract was presented at the Canadian Association of Emergency Physicians conference in Montreal, OC, in June 2010.

Correspondence to: Dr. Julien Payrastre, C/O Abbotsford Regional Hospital and Cancer Centre, 32900 Marshall Road, Abbotsford, BC V2S 0C2; Payrastre@gmail.com.

This article has been peer reviewed. 
palpation du thorax (SCRAP [acronyme anglais]). Dans le groupe de validation, ces cinq mêmes variables avaient une sensibilité de $100 \%$ (IC à 95\% 96.2-100), une spécificité de $44.7 \%$ (IC à 95\% 39.5-44.7), et un rapport de vraisemblance négatif de 0.00 (IC à $95 \% 0.00-0.10$ ).

Conclusions: Dans cette étude rétrospective, les variables SCRAP avaient une sensibilité de $100 \%$ à l'égard des blessures thoraciques graves dans les cas de traumatisme contondant sérieux se traduisant par un résultat $>8$ sur l'EG. Les résultats restent à valider de façon prospective avant d'être appliqués en milieu clinique.

Keywords: chest computed tomography, clinical decision rule, trauma
Computed tomography (CT) is commonly used to rule out thoracic injury in patients suffering major blunt thoracic trauma. Many studies have confirmed its diagnostic value in this population, but there are few evidence-based guidelines that help the clinician identify which patients are at very low risk for thoracic injury and do not need chest CT. ${ }^{1}$ Currently, the decision on whether to perform chest CT is made mostly by clinical judgment, based on the patient's clinical condition and the mechanism of trauma. ${ }^{2}$

Clinical decision rules are clinical tools that use clinical variables or test results to help clinicians make decisions regarding diagnostic or therapeutic interventions for patients. Typically, these rules identify very low-risk patients who do not need the test or intervention being studied. Many clinical decision rules have been developed, validated, and implemented in emergency departments (EDs) to make reliable imaging decisions in a variety of injury situations (e.g., the Ottawa Ankle Rules, the Canadian C-spine Rule, and the Canadian CT Head Rule)..$^{3-5}$ The goal of this study was to derive and internally validate a clinical decision rule that will identify blunt trauma patients at very low risk for major thoracic injury with 100\% sensitivity, thereby eliminating the need for chest CT.

\section{METHODS}

\section{Study design}

This study was a retrospective medical record review of trauma patients at a single trauma centre in southern Ontario from 2005 to 2008 . The study was designed to derive and validate a clinical decision rule that identified patients at low risk for major thoracic injury.

\section{Ethics}

This study was approved by the Research Ethics Board at Hamilton Health Sciences.

\section{Patient population}

All patients from 2005 to 2008 (inclusive) presenting to an adult tertiary trauma care centre in southern Ontario were eligible. The hospital has a catchment area of over 2 million people.

\section{Inclusion and exclusion criteria}

Patients were included in the study if their arrival in the ED triggered trauma team activation, they had suffered blunt trauma, and they underwent chest $\mathrm{CT}$ as part of their initial assessment. The regional trauma team activation guidelines are as follows: the trauma team activation requires that patients meet physiologic criteria (e.g., Glasgow Coma Scale [GCS] score $<14$, systolic blood pressure $<90 \mathrm{~mm} \mathrm{Hg}$, respiratory rate $<10$ or $>30$ breaths/min) injury criteria (e.g., penetrating injury to the head, neck, trunk, or groin; spinal cord injury; amputation above the wrist or ankle; two or more long bone fractures; pelvis fracture; flail chest; open or depressed skull fracture), mechanism criteria (e.g., fall $>6 \mathrm{~m}$ [20 ft], high-risk automobile or motorcycle crash, pedestrian v. vehicle crash), or "high-risk" criteria (e.g., older age, associated burns, pregnancy, bleeding disorders, paramedic judgment).

Patients were excluded if they had penetrating injuries or signs of paralysis. Patients with a GCS score $<9$ and those who were intubated prior to thoracic assessment were also excluded as previous studies have shown that thoracic tenderness is an important predictor of major thoracic injury and these patients would be unable to provide this information. ${ }^{2,6,7}$ It was felt that as a result of their inability to communicate, these patients would not qualify as low risk for major thoracic injuries. The trauma database that was used to identify the patient population only includes patients older than 15 years with an Injury Severity Score (ISS) $>12$. As a result, patients $<16$ years of age or with an ISS $<13$ were excluded. 


\section{Data collection}

Three data collectors (L.S., R.C., and H.P.) independently abstracted the study variable data for all included trauma patients seen during the study period. These clinical variables were derived from published studies and local expert opinion. The data were abstracted from the patient's electronic records and entered onto a study-specific data abstraction form. As there were multiple sources of data in the patient charts, a priori we established the hierarchy of data sources. The trauma staff or fellow's dictated note was the primary source of information as this was the physician making the decision whether to obtain a chest CT scan. If this was unavailable or incomplete, the abstractors were to refer to notes from other physicians who participated in the trauma resuscitation and then the nursing notes.

Although the data abstractors were not blinded to the study objectives, they had no knowledge of which variables were likely to be included in the final rule. The abstractors were not blinded to patient outcomes or CT results as these are generally included in the trauma chart and admission note. The variables collected included age, sex, mechanism, extraction time, seat belt use, air bag deployment, patient ejection from vehicle, heart rate at the time of assessment, respiratory rate, oxygen saturation, supplemental oxygen use, systolic blood pressure, abnormal auscultation of the chest, abnormal findings on thoracic palpation (anteriorly or posteriorly), acute abnormalities on a chest radiograph, findings on a chest CT scan, GCS score at arrival, intubation on arrival, intubation after initial assessment, tube thoracostomy insertion (initial or delayed), specific thoracic injuries diagnosed, length of stay in hospital, ISS, ICD-9 data, and patient identification number. We calculated interrater reliability between the data abstractors using a percent agreement score for each of the clinical variables on the first 91 charts $(10 \%$ of total charts). Disagreements between the abstractors were resolved by consensus or adjudication by the principal investigator (J.P.).

\section{Outcome measures}

The primary outcome measure was the presence of a major thoracic injury noted on a CT scan, at discharge, or at clinic follow-up. We defined a major thoracic injury as any thoracic injury that could potentially change clinical management in that it may need a specific therapy or a period of in-hospital observation. Injuries considered to be major thoracic injuries were aortic or great vessel injury, diaphragmatic injury, flail segment, esophageal injury, hemothorax, pneumothorax, mediastinal or paravertebral hematoma, pneumomediastinum, cardiac injury, scapula fracture, and thoracic spine fracture (excluding spinous and transverse process). Conversely, we defined a minor thoracic injury as any thoracic injury for which obtaining a chest CT scan would not change clinical management. Based on published studies and expert opinion, we identified five thoracic injuries as minor: clavicle fractures, rib fractures without a flail segment, ${ }^{8}$ pulmonary contusions, ${ }^{9,10}$ transverse process fractures, ${ }^{11}$ and spinous process fractures. We chose this composite outcome of major thoracic injury because it provides a clear course of action: whether or not to do chest CT. Outcomes related to mortality, morbidity, or surgery may still leave the question of whether a CT scan is needed unclear.

\section{CT chest technique}

CT scanning of the thorax was performed on a 64detector unit (Aquilion, Toshiba America Medical Systems, Tustin, CA). As per local protocol, all patients received $100 \mathrm{~mL}$ of intravenous contrast (Visipaque 270 at $3 \mathrm{~mL} / \mathrm{s})$. Reconstructed section thickness was $3 \mathrm{~mm}$ (nonoverlapping). The staff radiologists' final interpretation of the CT scans and chest radiographs was abstracted from the patient's electronic hospital records. An abnormal chest radiograph was defined as any chest radiograph with an acute change or abnormality that could be due to trauma.

\section{Statistical analysis}

Once collected, the data were divided into two groups. The first data group (3 years from January 2005 to March 2006 and April 2007 to December 2008) was used to derive the clinical decision rule, and the second data group (1 year from April 2006 to March 2007) was used to internally validate the clinical decision rule. This method was chosen to ensure that the validation population was similar to the derivation population to test the internal validity of the clinical decision rule. 
Continuous variables were dichotomized by receiver operating characteristic curve analysis to determine one or more clinically meaningful cutoffs with a low likelihood ratio. Predictor variables that could not be immediately obtained or reliably confirmed by the clinician in the trauma suite on patient arrival were not included as possible predictor variables for the clinical decision rule.

We used univariate techniques to determine the strength of the association between predictor variables and major thoracic injury. We used recursive partitioning to combine variables that were strongly associated with major thoracic injury $(p<0.1)$ (e.g., chest radiograph, respiratory rate, chest auscultation, heart rate, thoracic palpation) or had strong face validity (e.g., mechanism, oxygen saturation, age, blood pressure) to find the best combination of predictor variables that were $100 \%$ sensitive for detecting the outcome measure while also producing the maximum possible specificity. To increase the discriminatory power of the model, we included predictor variables that were not significant on univariate analysis but had face validity as potential items in the recursive partitioning model in case these variables became significant in subgroup partitions. ${ }^{12} \mathrm{We}$ used a chisquared recursive partitioning model created using OptimusRP software version 4.2.1 (Golden Helix Inc., Bozeman, MT). This method recursively splits the patient population into sets and subsets of subgroups based on the predictor variables. We chose this method of multivariate analysis because recursive partitioning provides a rule with very high sensitivity, whereas logistic regression creates rules with higher overall accuracy, to the detriment of less sensitivity. ${ }^{12,13} \mathrm{We}$ felt that lowering the sensitivity from $100 \%$ in the detection of chest trauma would be unacceptable to most clinicians and therefore used recursive partitioning.

We performed sensitivity analyses to explore the performance of the rule with different predictor variable dichotomization, blunt aortic traumatic injury as an outcome, and logistic regression model development.

\section{RESULTS}

\section{Patient characteristics}

A total of 614 patients (434 in the derivation and 180 in the validation) were included in this study (Figure 1).

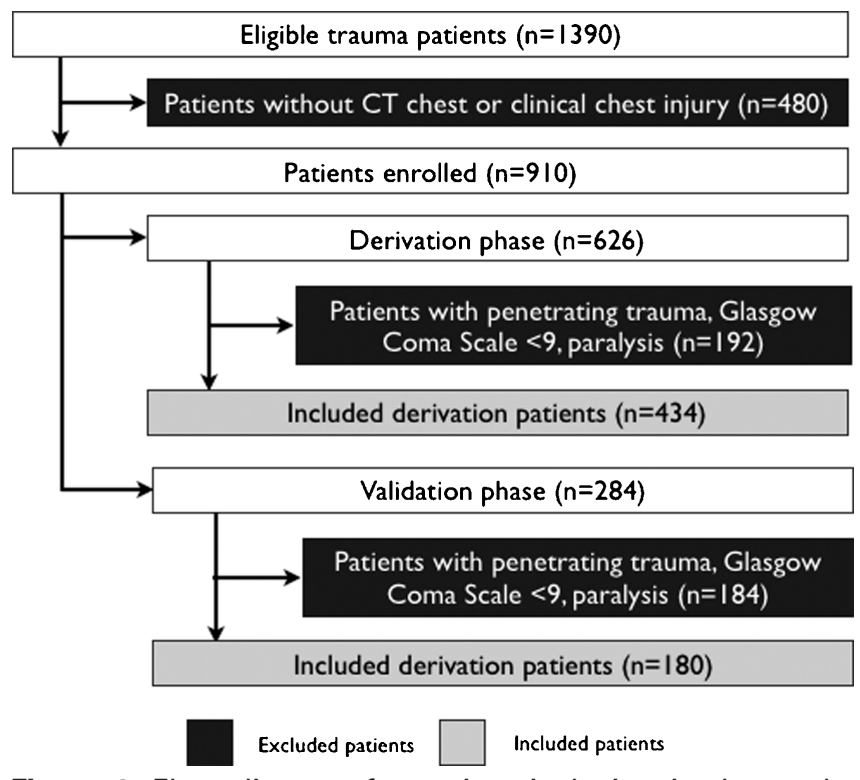

Figure 1. Flow diagram for patient inclusion in the study. Patients were excluded if they did not have either chest computed tomography (CT) or thoracic injury in the trauma database. The groups were then divided into derivation and validation groups. Patients were also excluded if they had penetrating trauma, a Glasgow Coma Scale score $<9$, or signs of paralysis. This left 434 patients in the derivation group and 180 patients in the validation group.

The characteristics of included patients are shown in Table 1.

\section{Derivation set}

There were 434 patients who met the inclusion criteria, of whom 274 had a major thoracic injury. The univariate association of the collected variables with major thoracic injury can be found in Table 2 . The percent agreement scores of the collected variables are also described in Table 2. The overall three-way agreement of the data collectors was $91.5 \%$. The incidence of thoracic injuries can be found in Table 3.

Recursive partitioning identified five variables that together had $100 \%$ sensitivity in detecting major thoracic injury (Figure 2). These five variables included abnormal oxygen saturation, chest radiograph, respiratory rate, chest a uuscultation, and thoracic palpation (Figure 3). From these, we created the acronym SCRAP. When all five of these variables were normal (SCRAP negative), no patient was found to have a major thoracic injury (sensitivity 100\% [95\% CI: 98.4100], specificity 46.9\% [95\% CI 44.2-46.9], likelihood ratio [LR] 0.00 [95\% CI 0.00-0.04], positive predictive 


\begin{tabular}{|lcc|}
\hline Table 1. Patient characteristics & & \\
\hline Characteristic & Derivation $(n=434)$ & Validation $(n=180)$ \\
\hline Age, yr, mean (range) & $43(16-95)$ & Median $=44$ \\
& Median $=44$ & 70.5 \\
Sex, \% male & 72.3 & 49.4 \\
Mechanism of injury & & 7.8 \\
Motor vehicle collision, \% & 52.3 & 3.3 \\
Motorcycle crash, \% & 9.4 & 8.3 \\
Bicycle crash, \% & 2.8 & 22.2 \\
Pedestrian (v. vehicle), \% & 5.1 & 0.6 \\
Fall from height, \% & 22.1 & 8.3 \\
Blunt assault, \% & 1.4 & $23(15-50)$ \\
Other mechanism, \% & 6.9 & $104 / 180(57.8)$ \\
ISS, mean (range) & $22(13-59)$ & $33 / 180(18.3)$ \\
Patients with major thoracic injury, $n(\%)$ & $274 / 434(63.1)$ & $76 / 180(42.2)$ \\
Minor thoracic injury (without major injury), $n(\%)$ & $70 / 434(16)$ & \\
Chest CT with no major thoracic injury, $n(\%)$ & $160 / 434(36.9)$ & \\
\hline CT = computed tomography; ISS = Injury Severity Score. & & \\
\hline
\end{tabular}

value [PPV] 76.3\% [95\% CI 75.1-76.3], and negative predictive value [NPV] $100 \%$ [95\% CI 94.2-100]) (Table 4).

The statistical significance of the SCRAP variables within the recursive partitioning model is presented in Table 2. If the SCRAP rule were applied to this population, there would be a $17 \%$ absolute reduction in CT scans, a 47\% reduction in negative CT scans, and no missed major thoracic injuries.

\section{Validation set}

There were 180 patients who met the inclusion criteria, of whom 104 had a major thoracic injury. Once again, the five SCRAP variables were found to be highly predictive of injury, and when none of these variables were present, no patients had a major thoracic injury (sensitivity 100\% [95\% CI 96.2-100], specificity 44.7\% [95\% CI 39.5-44.7], negative LR 0.00 [95\% CI 0.000.10], PPV 71.9\% [95\% CI 68.5-71.2], and NPV 100\% [95 CI 88.3-100]) (Table 5). In the validation population, 104 of $180(57.8 \%)$ patients were found to have a major thoracic injury. If the SCRAP rule were applied to this population, there would be a $19 \%$ absolute reduction in CT scans, a $45 \%$ reduction in negative CT scans, and no missed major thoracic injury.

\section{Sensitivity analysis}

Twenty-eight patients with rib, clavicle, or spinous process fractures were documented to have no thoracic tenderness; this may have been a product of underreporting in this retrospective review. We conducted a post hoc sensitivity analysis with the assumption that patients who had rib fractures would have been positive for tenderness on palpation. Using recursive partitioning, the same five variables were found to predict major thoracic injury with the following characteristics for predicting major thoracic injury: sensitivity 100\% (95\% CI 98.4-100), specificity 35.7\% (95\% CI 32.935.7), and LR 0.00 (95\% CI 0.00-0.05). Again, no causes of major thoracic injury were missed, but including these patients as SCRAP positive yielded an $11 \%$ absolute reduction in CT scans.

The test characteristics of the SCRAP rule for the sole outcome of blunt aortic traumatic injury in the derivation group was sensitivity $100 \%$ (95\% CI $66.2-$ 100), specificity $17.7 \%$ (95\% CI $16.9-17.7$ ), and LR 0.00 (95\% CI $0.00-2.00$ ).

To compare an alternative method to recursive partitioning for creating the rule, forward stepwise logistic regression analysis yielded a four-variable model from the derivation group (abnormal chest radiograph, respiratory rate $>20$ breaths/min, abnormal auscultation, and abnormal palpation), with a sensitivity of $98 \%$ (95\% CI 96-99) and a specificity of $45 \%$ (95\% CI 39-52).

\section{DISCUSSION}

This study was designed to determine if a clinical decision rule could be created that would identify blunt 


\begin{tabular}{|c|c|c|c|}
\hline Clinical variable & $\begin{array}{l}\text { Three-person } \\
\% \text { agreement }\end{array}$ & $\begin{array}{l}\text { Unadjusted } \\
\text { (univariate) } \\
\text { odds ratio, } p\end{array}$ & $\begin{array}{c}\text { Significance in } \\
\text { RP } \\
\text { model, } p\end{array}$ \\
\hline \multicolumn{4}{|l|}{ SCRAP variables } \\
\hline $\mathrm{SpO}_{2}<95 \%$ on room air or $<98 \%$ on supplement oxygen ( $n=81$ ) & 84.7 & $1.37(0.82-2.39), 0.25$ & $<0.001$ \\
\hline Abnormal chest radiograph $(n=165)$ & 97.8 & $10.65(6.10-18.58),<0.0001$ & $<0.001$ \\
\hline $\mathrm{RR}>24(n=69)$ & 90.0 & $1.91(1.07-3.40), 0.04$ & $<0.001$ \\
\hline Abnormal chest auscultation $(n=154)$ & 86.6 & $4.85(2.30-7.86),<0.0001$ & 0.001 \\
\hline Abnormal thorax palpation anteriorly or posteriorly $(n=201)$ & 76.6 & $4.11(2.68-6.29),<.0001$ & $<0.001$ \\
\hline \multicolumn{4}{|l|}{ Variables not included in SCRAP } \\
\hline Age $\geq 55$ yr $(n=140)$ & 100 & $1.06(0.70-1.60), 0.89$ & N/A \\
\hline Age $\geq 60$ yr $(n=110)$ & 100 & $1.10(0.70-1.72), 0.76$ & N/A \\
\hline Age $\geq 65$ yr $(n=76)$ & 100 & $0.99(0.60-1.65), 0.92$ & N/A \\
\hline Age $\geq 70$ yr $(n=57)$ & 100 & $0.70(0.40-1.22), 0.26$ & N/A \\
\hline Age $\geq 80(n=28)$ & 100 & $0.51(0.24-1.10), 0.12$ & N/A \\
\hline Male sex $(n=314)$ & 100 & $0.84(0.54-1.30), 0.49$ & N/A \\
\hline \multicolumn{4}{|l|}{ Mechanism } \\
\hline $\operatorname{MVC}(n=227)$ & 99.6 & $1.50(1.02-2.21), 0.05$ & N/A \\
\hline Motorcycle $(n=41)$ & 99.6 & $0.61(0.32-1.17), 0.19$ & N/A \\
\hline Pedestrian $(n=22)$ & 99.6 & $0.72(0.31-1.70), 0.61$ & N/A \\
\hline Bicycle $(n=12)$ & 99.6 & $0.60(0.19-1.91), 0.54$ & N/A \\
\hline Blunt assault $(n=6)$ & 99.6 & $0.30(0.06-1.66), 0.20$ & N/A \\
\hline Fall $(n=96)$ & 99.6 & $1.03(0.64-1.64), 0.92$ & N/A \\
\hline \multicolumn{4}{|l|}{ MVC } \\
\hline Ejected $(n=24)$ & 95.1 & $1.58(0.60-4.16), 0.48$ & N/A \\
\hline Air bag deployed $(n=46)$ & 94.0 & $0.58(0.30-1.13), 0.15$ & N/A \\
\hline Seat belt used $(n=140)$ & 96.3 & $1.07(0.61-1.89), 0.92$ & N/A \\
\hline Extrication $>5 \min (n=70)$ & 92.6 & $1.14(0.63-2.09), 0.77$ & N/A \\
\hline \multicolumn{4}{|l|}{ Oxygen saturation } \\
\hline$<98 \%(n=117)$ & 84.7 & $1.54(0.98-2.42), 0.08$ & N/A \\
\hline$<95 \%(n=51)$ & 88.1 & $1.39(0.74-2.61), 0.37$ & N/A \\
\hline \multicolumn{4}{|l|}{ Heart rate (beats/min) } \\
\hline$\geq 100(n=144)$ & 89.9 & $2.07(1.34-3.20), 0.001$ & N/A \\
\hline$\geq 110(n=91)$ & 89.9 & $2.09(1.24-3.51), 0.007$ & N/A \\
\hline \multicolumn{4}{|l|}{ Respiratory rate (breaths/min) } \\
\hline$\geq 21(n=169)$ & 84.0 & $2.50(1.64-3.81),<0.0001$ & N/A \\
\hline$\geq 30(n=27)$ & 92.9 & $2.50(1.64-3.81),<0.0001$ & N/A \\
\hline \multicolumn{4}{|l|}{ Systolic BP (mm Hg) } \\
\hline$<110(n=64)$ & 95.1 & $1.54(0.87-2.74), 0.18$ & N/A \\
\hline$<100(n=35)$ & 95.5 & $1.78(0.81-3.91), 0.20$ & N/A \\
\hline$<90(n=17)$ & 96.6 & $1.49(0.52-4.32), 0.62$ & N/A \\
\hline \multicolumn{4}{|l|}{ GCS score } \\
\hline $9-13(n=60)$ & 92.9 & $1.07(0.61-1.88), 0.92$ & N/A \\
\hline$>13(n=374)$ & 92.9 & $0.93(0.53-1.65), 0.92$ & N/A \\
\hline
\end{tabular}

$\mathrm{BP}=$ blood pressure; GCS = Glasgow Coma Scale; $\mathrm{MVC}=$ motor vehicle collision; N/A = not available; $\mathrm{RP}=$ recursive partitioning; $\mathrm{RR}=$ respiratory rate; $\mathrm{SCRAP}=$ abnormal oxygen saturation, chest radiograph, respiratory rate, chest auscultation, and thoracic palpation; $\mathrm{SpO}_{2}=$ saturated oxygen.

trauma patients at very low risk for major thoracic injury. In this preliminary study, it appears that the SCRAP rule correctly identifies these patients with $100 \%$ sensitivity. To our knowledge, there are currently no accepted guidelines that suggest to clinicians which patients are at low risk for major thoracic injury in blunt trauma and few that suggest when to obtain a chest CT scan..$^{1,2}$ The American College of Radiology suggests that CT should be done if the chest radiograph shows signs of aortic injury. ${ }^{14}$ Given that major thoracic injuries (major thoracic injury) in blunt trauma can significantly increase 


\begin{tabular}{|c|c|c|c|c|c|}
\hline & \multicolumn{2}{|c|}{ Derivation group } & \multicolumn{2}{|c|}{ Validation group } & \multirow[b]{2}{*}{$\begin{array}{c}\text { Total } \\
(N=614)\end{array}$} \\
\hline & $\begin{array}{c}\text { SCRAP } \\
\text { negative } \\
(n=75)\end{array}$ & $\begin{array}{l}\text { SCRAP } \\
\text { positive } \\
(n=359)\end{array}$ & $\begin{array}{c}\text { SCRAP } \\
\text { negative } \\
(n=34)\end{array}$ & $\begin{array}{l}\text { SCRAP } \\
\text { positive } \\
(n=146)\end{array}$ & \\
\hline \multicolumn{6}{|l|}{ Major thoracic injuries (may change management) } \\
\hline Aortic (or great vessel) injury & 0 & 10 & 0 & 3 & 13 \\
\hline Diaphragm injury & 0 & 6 & 0 & 2 & 8 \\
\hline Flail segment & 0 & 28 & 0 & 17 & 45 \\
\hline Esophageal injury & 0 & 0 & 0 & 0 & 0 \\
\hline Hemothorax/pneumothorax & 0 & 196 & 0 & 83 & 279 \\
\hline Mediastinal or paravertebral hematoma/pneumomediastinum & 0 & 54 & 0 & 26 & 80 \\
\hline Any cardiac injury (including contusion) & 0 & 3 & 0 & 1 & 4 \\
\hline Scapula fracture & 0 & 41 & 0 & 19 & 60 \\
\hline Sternal fracture & 0 & 48 & 0 & 12 & 60 \\
\hline Thoracic spine fracture (excluding spinous and transverse process) & 0 & 59 & 0 & 19 & 78 \\
\hline \multicolumn{6}{|l|}{ Minor thoracic injuries (CT will not change management) } \\
\hline Clavicle fracture & 2 & 48 & 1 & 19 & 70 \\
\hline Pulmonary contusion/atelectasis & 19 & 227 & 6 & 111 & 366 \\
\hline Rib fractures without flail segment & 19 & 219 & 4 & 81 & 323 \\
\hline Spinous process fracture & 2 & 21 & 0 & 12 & 35 \\
\hline Transverse process fracture ${ }^{22}$ & 0 & 34 & 0 & 9 & 43 \\
\hline
\end{tabular}

morbidity and mortality, the ability to confidently rule out major thoracic injury is paramount. This has led to the widespread use of chest CT, with some physicians even advocating CT scanning all blunt trauma patients from the head to the pelvis. ${ }^{15}$ A recent study suggested that $28 \%$ (33 of 112) of blunt thoracic injuries would have been missed without chest CT, including 7 hemothoraces but no blunt thoracic aortic injuries. ${ }^{16}$ However, in the same study, 14 patients with rib fractures and 6 with either clavicle or scapular fractures were completely unsuspected. This was perhaps a result of intubated or unresponsive patients being included in the study population. Published results reveal that approximately half of the thoracic CT scans obtained in blunt trauma are negative for major thoracic injury (61\% in the previous study), ${ }^{2,16}$

Studies of blunt trauma patients in need of advanced imaging have focused on identifying trauma patients at greatest risk for major thoracic injury and comparison of diagnostic performance between chest radiography and CT. ${ }^{6,7,17-23}$ One study did attempt to identify very low-risk patients who did not need chest CT, but it was only $95 \%$ sensitive. ${ }^{2}$

Reducing the number of unnecessary CT scans is in the best interest of both the patient and the clinician for many reasons. First, there is increasing evidence that radiation exposure from a CT scan may cause more significant long-term damage than was first evident, especially in younger patient populations. ${ }^{24}$ Second, hospitals without 24-hour CT are forced to transfer trauma patients after hours. Third, the time spent in the CT scanner suite can potentially exacerbate a patient's condition and potentially delay transfer to the operating room for definitive repair of other injuries. ${ }^{25}$ Fourth, false positive CT scans can lead to other invasive tests and procedures and subsequent complications. Fifth, contrast-induced nephropathy and anaphylactoid reactions are well-documented complications of contrast dye that should be avoided if possible. ${ }^{26}$ Sixth, there are significant financial costs associated with CT scans. For all of these reasons, there is a need for reliable clinical criteria that will help reduce the number of negative thoracic CT scans in blunt trauma.

This study was designed to determine if a clinical decision rule could be created that would identify blunt trauma patients at very low risk for major thoracic injury who do not need chest CT. It appears that the SCRAP rule identifies these patients with up to $100 \%$ sensitivity. The results of this study suggest that if all of 


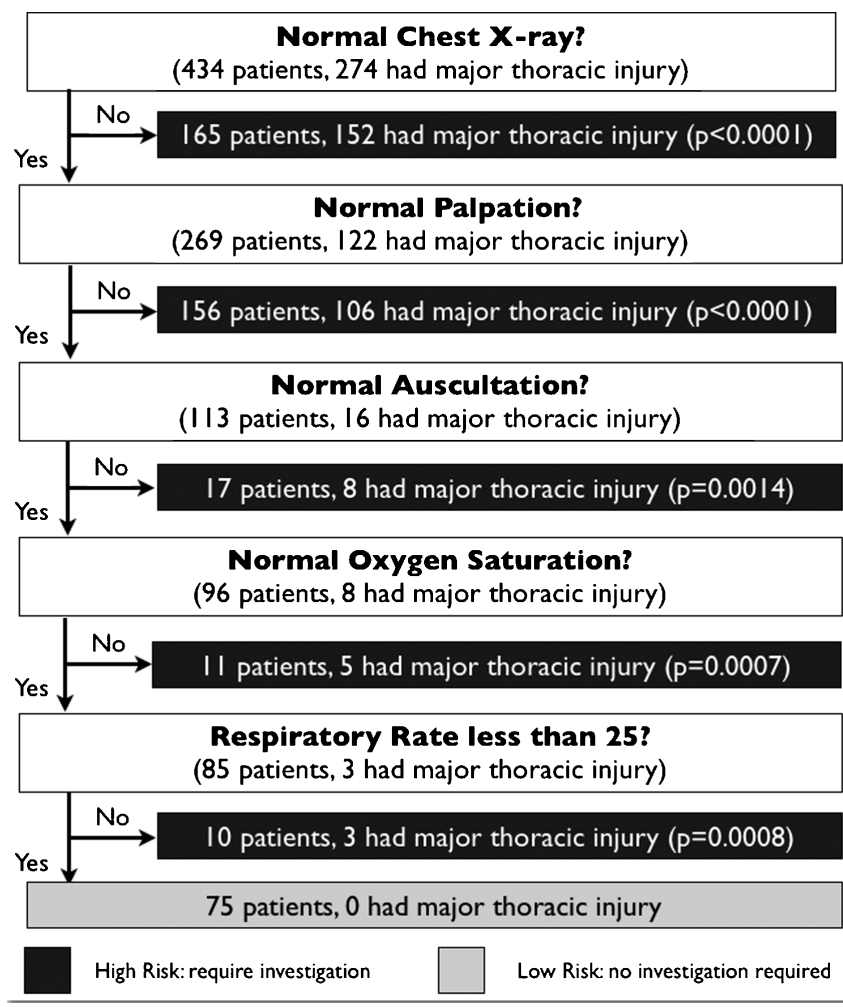

Figure 2. Recursive partitioning tree created from the study data. Starting at the top of the diagram, 434 patients were included. The first branch shows that 269 patients had a normal chest radiograph and 165 patients did not. Of the 165 patients with an abnormal chest radiograph, 152 had a major thoracic injury (MTI). The second branch points show that of the 269 patients who had a normal chest radiograph, 113 had normal palpation of the chest and 156 did not. The figures continues to branch down through auscultation, oxygen saturation, and respiratory rate. The final branch point on the left side of the diagram shows that of the 75 patients who had no abnormalities, none had MTI.

the SCRAP variables are normal, a clinically important major thoracic injury can be excluded; therefore, the patient does not need chest CT.

This study found that our trauma centre could have performed $17 \%$ fewer chest CT scans in blunt thoracic trauma per year. There were 13,282 blunt trauma patients in the National Trauma Registry for the 2008-2009 reporting period (April 1, 2008, to March $31,2009) .{ }^{27}$ If the number of unnecessary CT scans for blunt thoracic trauma could be reduced in all trauma centres and community settings, the potential savings in unnecessary CT costs and patient radiation exposures could be significant.

Interestingly, oxygen saturation was found to be highly statistically significant in the recursive partitioning model $(p<0.001)$; however, it was not significant in the univariate analysis. This finding was likely due to the

\begin{tabular}{|c|c|}
\hline \multicolumn{2}{|c|}{ When to SCRAP the CT Chest } \\
\hline Variable & What is considered 'normal' \\
\hline Saturation & $\begin{array}{c}\geq 9 \% \text { on room air or } \geq 98 \% \text { on } \\
\text { supplemental oxygen }\end{array}$ \\
\hline Chest X-ray & No acute abnormalities \\
\hline Respiratory Rate & $\leq 24$ breaths per minute \\
\hline Auscultation of the Chest & No abnormalities \\
\hline Palpation of the Thorax & $\begin{array}{c}\text { No anterior or posterior tenderness or } \\
\text { crepitus }\end{array}$ \\
\hline \multicolumn{2}{|c|}{ If all five of the variables are normal: } \\
"SCRAP -ve"
\end{tabular}

Figure 3. Five variables that were included in the clinical decision rule created by this study. On the left is the name of the variable and on the right is the definition of the variable. The bottom row shows the definition of "SCRAP -ve": all five of the variables are normal. The title of the figure is a play on words that states that if the five variables are normal, chest computed tomography (CT) is not necessary.

existence of a subset of patients in this population for whom low oxygen saturation was highly important in predicting major thoracic injury. As can be seen in Figure 2 , at the oxygen saturation branch node, 5 of 11 (45\%) patients with abnormal saturation had major thoracic injury, whereas only 3 of $85(4 \%)$ with normal saturation had major thoracic injury $(p<0.001)$. In addition to being highly significant within the model, this variable also has significant face validity as a predictor of major thoracic injury.

\section{Limitations}

This clinical decision rule has some limitations and therefore is not yet ready for clinical use. The first limitation is that it has been derived and internally validated using a retrospective patient cohort. Due to the nature of retrospective analysis, there is the potential for many sources of bias. For instance, the trauma fellow's dictations are typically recorded after

\begin{tabular}{|c|c|c|}
\hline & \multicolumn{2}{|c|}{ Major thoracic injury } \\
\hline & Present & Absent \\
\hline SCRAP positive & 274 & 85 \\
\hline SCRAP negative & 0 & 75 \\
\hline
\end{tabular}




\begin{tabular}{|c|c|c|}
\hline & \multicolumn{2}{|c|}{ Major thoracic injury } \\
\hline & Present & Absent \\
\hline SCRAP positive & 104 & 42 \\
\hline SCRAP negative & 0 & 34 \\
\hline
\end{tabular}

the resuscitation, so the clinical variables may not accurately reflect the findings on initial examination. The fact that we only enrolled patients who had chest CT is another limitation. This limits the generalizability of the rule and our ability to calculate a true specificity.

Another limitation of this study was that the data collectors were blinded to the study question but not to patient outcomes. Also, the fact that 28 patients with rib, clavicle, or spinous process fractures were documented to have no thoracic tenderness (and thus were SCRAP negative) seems inconsistent. This variable was inconsistently reported in the patient records and even when reported was often vague. Due to this inconsistency in reporting, the interrater percent agreement for this variable was $76.6 \%$. This stems from multiple circumstances in which one of the data abstractors could not find the information in the written doctor's notes. When this occurred, the variable was calculated as absent-a "worst case scenario" analysis, giving a more conservative estimation of sensitivity. Had these patients been documented to have thoracic tenderness, this clinical decision rule would have had a lower specificity but retained its $100 \%$ sensitivity.

Another limitation is that the chest radiographs were interpreted by staff radiologists. The physician in the trauma suite or ED who is reading the chest radiograph is often not a radiologist, which may decrease the accuracy and reliability of this variable. Finally, the number of blunt thoracic aortic injuries captured in this study was small (13 patients), but all were detected by the SCRAP rule. Several studies have suggested that the combination of a chest radiograph and clinical variables may be able to rule out blunt thoracic aortic injuries, but none had an adequately high sensitivity to rule out the disease. ${ }^{8}$ Although future studies will ideally have a sufficient number of aortic injuries to confirm whether they are detected by the SCRAP rule, based on the current study's prevalence of $2 \%$, this would require a large study with approximately 4,753 included blunt trauma patients to obtain a sensitivity of $99 \%$ with a $95 \%$ CI width of $2 \%$.

Of note, certain variables analyzed in this study that have previously been noted to be predictors of thoracic injury (such as mechanism) were not included in the final clinical decision rule. The reason for this is simply that they were not required to achieve $100 \%$ sensitivity in detecting patients at low risk for major thoracic injury. These variables, once collected and analyzed, were not found to be as useful within the recursive partitioning model as the five SCRAP variables. In future validation studies, if injuries are missed (such as aortic injuries), then these variables may be required to maintain a sensitivity of $100 \%$; however, the results of this study suggest that they are not required.

\section{Clinical implications and use}

As designed, this clinical decision rule is meant to be applied to major blunt trauma patients who have a GCS score $>8$. If any one of the five clinical variables of the SCRAP clinical decision rule is abnormal, the patient is not at low risk for major thoracic injury, and the clinician must decide whether to obtain a CT scan based on the clinical impression. If all five of the variables are normal, then the patient is at low risk for major thoracic injury, and chest CT is not required. The next step for this clinical decision rule should be a prospective multicentre validation to confirm the results found in this retrospective study. This study constitutes a level IV clinical decision rule that requires external validation and implementation studies. ${ }^{28}$

\section{CONCLUSION}

This retrospective study has derived and internally validated the SCRAP rule for excluding major thoracic injuries in blunt trauma. The SCRAP variables are $100 \%$ sensitive for major thoracic injury, and their absence rules out major thoracic injury. This level IV clinical decision rule still requires external validation in multiple settings and as such is not ready for clinical use.

Competing interests: None declared.

\section{REFERENCES}

1. Brink M, Kool DR, Dekker HM, et al. Predictors of abnormal CT chest after blunt trauma: a critical appraisal of 
the literature. Clin Radiol 2005;64:272-83, doi:10.1016/j. crad.2008.09.004.

2. Brink M, Deunk J, Dekker HM, et al. Criteria for the selective use of chest computed tomography in blunt trauma patients. Eur Radiol 2010;20:818-28, doi:10.1007/s00330009-1608-y.

3. Stiell IG, Greenberg GH, McKnight RD, et al. Decision rules for the use of radiography in acute ankle injuries. Refinement and prospective validation. FAMA 1993;269: 1127-32, doi:10.1001/jama.269.9.1127.

4. Stiell IG, Clement CM, Grimshaw J, et al. Implementation of the Canadian C-Spine Rule: prospective 12 centre cluster randomised trial. BMF 2009;339:b4146, doi:10.1136/bmj. $\underline{\mathrm{b} 4146 .}$

5. Stiell IG, Wells GA, Vandemheen K, et al. The Canadian CT head rule for patient with minor head trauma. Lancet 2001;357:1391-6, doi:10.1016/S0140-6736(00)04561-X.

6. Traub M, Stevenson M, McEvoy S, et al. The use of chest computed tomography versus chest $\mathrm{x}$-ray in patients with major blunt trauma. Injury 2007;38:43-7, doi:10.1016/j. injury.2006.07.006.

7. Bokhari F, Brakenridge S, Nagy K, et al. Prospective evaluation of the sensitivity of physical examination in chest trauma. 7 Trauma 2002;53:1135-8, doi:10.1097/00005373200212000-00017.

8. Marts B, Durham R, Shapiro M, et al. Computed tomography in the diagnosis of blunt thoracic injury. Am 7 Surg 1994;168:688-92, doi:10.1016/S0002-9610(05)80146-1.

9. Johnson JA, Cogbill TH, Winga ER. Determinants of outcome after pulmonary contusion. 7 Trauma 1986;26:6957, doi:10.1097/00005373-198608000-00002.

10. Kwon A, Sorrells DL, Kurkchubasche AG, et al. Isolated computed tomography diagnosis of pulmonary contusion does not correlate with increased morbidity. 7 Pediatr Surg 2006;41:78-82, doi:10.1016/j.jpedsurg.2005.10.009.

11. Bradley LH, Paullus WC, Howe J, et al. Isolated transverse process fracture: spine service management not needed. $\mathcal{F}$ Trauma 2008;65:832-6, doi:10.1097/TA.0b013e318184d30e.

12. Cook EF, Goldman L. Empiric comparison of multivariate analytic techniques: advantages and disadvantages of recursive partitioning analysis. F Chron Dis 1984;37:721-31, doi:10.1016/ 0021-9681(84)90041-9.

13. Stiell IG, Wells GA. Methodologic standards for the development of clinical decision rules in emergency medicine. Ann Emerg Med 1999;33:437-47, doi:10.1016/S01960644(99)70309-4.

14. Holtzman SR, Yucel EK, Rybicki FJ, et al. American College of Radiology Appropriateness Criteria - suspected aortic injury (2009). Available at: http://acsearch.acr.org/default.aspx (accessed June 16, 2010).

15. Salim A, Sangthong B, Martin M, et al. Whole body imaging in blunt multisystem trauma patients without obvious signs of injury. Arch Surg 2006;141:468-75, doi:10.1001/archsurg.141.5.468.
16. Tillou A, Gupta M, Baraff L, et al. Is the use of pancomputed tomography for blunt trauma justified? A prospective evaluation. 7 Trauma 2009;67:779-87, doi:10.1097/ TA.0b013e3181b5f2eb.

17. Rodgriguez RM, Hendey GW, Marek G, et al. A pilot study to derive clinical variables for the selective chest radiography in blunt chest trauma patients. Ann Emerg Med 2006;47:4158, doi:10.1016/j.annemergmed.2005.10.001.

18. Ungar TC, Wolf SJ, Haukoos JS, et al. Derivation of a clinical decision rule to exclude thoracic aortic imaging in patients with blunt chest trauma after motor vehicle collisions. $f$ Trauma 2006;61:1150-5, doi:10.1097/01.ta. $\underline{0000239357.68782 .30 \text {. }}$

19. Deunk J, Dekker HM, Brink M, et al. The value of indicated computed tomography scan of the chest and abdomen in addition to the conventional radiologic work-up for blunt trauma. I Trauma 2007;63:757-63, doi:10.1097/01.ta. $0000235878.42251 .8 \mathrm{~d}$.

20. Ekeh AP, Perterson W, Woods RJ, et al. Is chest x-ray an adequate screening tool for the diagnosis of blunt thoracic aortic injury? 7 Trauma 2008;65:1088-92, doi:10.1097/ TA.0b013e31812f60bf.

21. Exadaktylos AK, Sclabas G, Schmid SW, et al. Do we really need routine computed tomographic scanning in the primary evaluation of blunt chest trauma in patients with "normal" chest radiograph? f Trauma 2001;51:1173-6, doi:10.1097/ 00005373-200112000-00025.

22. Livingston DH, Shogan B, John P, et al. CT diagnosis of rib fractures and the prediction of acute respiratory failure. $\mathcal{F}$ Trauma 2008;64:905-11, doi:10.1097/TA.0b013e3181668ad7.

23. Fosse JP, Cohen Y, Karoubi P, et al. Initial evaluation of thoracic injuries. Comparison of pulmonary radiography and x-ray computed tomography. Presse Med 1997;26:1232-5.

24. Berrington de Gonzales A, Kim KP, Berg CD. Low-dose lung computed tomography screening before age 55: estimates of the mortality reduction required to outweigh the radiation-induced cancer risk. $\mathcal{F}$ Med Screen 2008;15:1538, doi:10.1258/jms.2008.008052.

25. Onzuka J, Worster A, McCreadie B. Is computerized tomography of trauma patients associated with a transfer delay to a regional trauma centre? CFEM 2008;10:205-8.

26. Tepel M, Aspelin P, Lameire N. Contrast-induced nephropathy. Circulation 2006;113:1799-806, doi:10.1161/CIRC ULATIONAHA.105.595090.

27. Canadian Institute for Health Information. National Trauma Registry 2011 report: Hospitalizations for Major Injury in Canada. 2008-2009 data. Available at: https://secure.cihi.ca/estore/ productFamily.htm?pf $=\mathrm{PFC1600 \& lang}=\mathrm{en} \&$ media $=0$.

28. McGinn TG, Guyatt GH, Wyer PC, et al. User's guide to the medical literature - XXII: how to use articles about clinical decision rules. 7AMA 2000;284:79-84, doi:10.1001/ jama.284.1.79. 